\title{
A política nacional de formação docente, o Programa Escola de Gestores e o trabalho docente
}

\section{The national policy for teachers' training, School of Managers Programme and teaching work}

\author{
Márcia Angela da S. Aguiar ${ }^{1}$
}

\begin{abstract}
RESUMO
O texto aborda a política nacional de formação de docentes da Educação Básica, focalizando o curso de especialização em gestão escolar oferecido pelas universidades federais, no âmbito do Programa Nacional Escola de Gestores, promovido pelo governo federal em articulação com as secretarias estaduais de educação. O artigo destaca a ação dos atores envolvidos no Programa e problematiza as condições de oferta do curso nas IFES e as repercussões no trabalho desses profissionais.

Palavras-chave: política de formação continuada de docentes da educação básica; Programa Nacional Escola de Gestores; curso de especialização em gestão escolar; trabalho docente.
\end{abstract}

\begin{abstract}
The article examines the national policy for teachers' training in Basic Education in Brazil, focusing on the post-graduate course on school management offered by the federal universities within the School of Managers National Programme, sponsored by the federal government in conjunction with state departments of education. It highlights the actions of the actors involved in the Programme and discusses the conditions of course supply in the federal universities and its impact on the work of these professionals.

Keywords: basic education Teachers' continuing education policy; School of Managers National Programme; post-graduate course on school management; teaching work.

1 Professora Titular do Centro de Educação da Universidade Federal de Pernambuco, Brasil.
\end{abstract} E-mail:marcia_angela@uol.com.br 


\section{Introdução}

A demanda pela instituição de um sistema nacional de formação de professores da Educação Básica esteve presente, desde o final da década de 1970, com o esgotamento do regime autoritário, na agenda dos setores organizados da sociedade brasileira. A garantia de formação continuada articulada à formação inicial e condições dignas de trabalho para os profissionais da educação básica, em especial para os professores, são reivindicações históricas que, em tese, deveriam ser contempladas com a instituição de um sistema nacional de educação.

Nessa direção, podem ser observados os movimentos dos educadores que se mobilizaram na organização das edições da Conferência Brasileira de Educação (CBE) e do Congresso Nacional de Educação (CONED), para citar as grandes mobilizações. Os documentos oriundos de todas essas manifestações apontam os temas mencionados como prioritários e que deveriam integrar a agenda pública.

Contudo, muito embora várias reivindicações dos setores organizados da educação tenham sido incorporadas à Lei de Diretrizes da Educação Nacional (LDBEN), lei nº 9.394, de 1996 e ao Plano Nacional de Educação (PNE), Lei $\mathrm{n}^{\circ} 10.172$, de 2001, a ideia da instituição de um sistema nacional de formação de professores contemplando a formação e as condições do trabalho docente somente terá espaço na agenda governamental no período de gestão do presidente Luiz Inácio Lula da Silva. Uma das explicações sobre a inscrição dessa demanda na agenda pública pode ser identificada na forma de relacionamento institucional que se instaurou entre o governo, representado pelo MEC, e entidades acadêmico-científicas de educadores, em especial, ANPEd, ANPAE, ANFOPE, FORUMDIR e CEDES 2 .

De forma similar, vários programas, projetos e ações governamentais contam com a participação de instituições e de entidades representativas do campo educacional que, de algum modo, buscam influenciar os rumos de políticas educacionais em curso, em que pesem estas terem ingredientes político-institucionais que ultrapassam os limites da interferência desses setores.

Como esse processo vem ocorrendo, pode ser observado em uma das ações programáticas do Executivo Federal, o Programa Nacional Escola de Gestores,

2 ANPEd - Associação Nacional de Pós-Graduação e Pesquisa em Educação; ANPAE Associação Nacional de Política e Administração da Educação; ANFOPE - Associação Nacional pela Formação dos Profissionais da Educação; FORUMDIR - Fórum Nacional de Diretores das Faculdades e Centros de Educação das Universidades Públicas; CEDES - Centro de Estudos Educação e Sociedade. 
o que permite problematizar as repercussões dessa ação no tocante à formação e ao trabalho docente no atual marco regulatório.

\section{O Programa Escola de Gestores e o processo de trabalho dos pro- fissionais da educação}

Uma das características do Governo Luiz Inácio Lula da Silva, em duas gestões, foi o de procurar o apoio da comunidade acadêmica universitária na etapa de formulação e implementação de programas e projetos educacionais. Pode-se atribuir tal postura de governo, de um lado, ao fato de que intelectuais de reconhecida atuação em várias entidades sindicais e acadêmicas do campo educacional passaram a ocupar cargos diretivos no Ministério de Educação e em secretarias estaduais e municipais de educação, o que lhes permitiu com facilidade estabelecer vias de contato permanente com esses setores.

E, de outro lado, a percepção de parte dos setores organizados da educação, identificados ou não com a plataforma governamental, de que a agenda estaria aberta e suscetível de redirecionamentos e de incorporação de outras demandas da área, argumento relevante para induzir a ampliação do nível de interlocução com as instâncias oficiais.

Com essas considerações, pode-se avançar na análise de um dos programas de âmbito nacional formulado pelo governo federal em 2004, o Programa Nacional Escola de Gestores da Educação Básica, do Ministério da Educação do Brasil, que visava a formação de professores-gestores que atuam na Educação Básica.

O Projeto Piloto Escola de Gestores foi instituído, no âmbito do Instituto Nacional de Estudos e Pesquisas Educacionais Anísio Teixeira - INEP, em 2004, na gestão do Ministro da Educação Tarso Genro (2003-2005) como uma iniciativa que visava a formação dos diretores das escolas e que deveria contribuir para a elevação da qualidade do ensino fundamental. Como justificativa para instituição deste Projeto, o governo apontava o baixo desempenho dos estudantes no Censo Escolar de 2004 e os resultados do Sistema de Avaliação Básica - SAEB. Afirmava que a melhoria da qualidade da educação nas escolas públicas estava relacionada com o fortalecimento de uma gestão escolar democrática, participativa e que garantisse mudanças ${ }^{3}$.

3 Vide o Projeto de Curso de Especialização em Gestão Escolar do Programa Nacional Escola de Gestores da Educação Básica no site do MEC < www.mec.gov.br> e o Folder Escola de Gestores da Educação Básica - Programa Nacional de Formação Continuada de Gestores Escolares. 
Vale destacar que o Projeto Piloto Escola de Gestores, muito embora fosse anunciado em pronunciamentos oficiais como um programa federal, sob a coordenação do Instituto Nacional de Estudos e Pesquisas Educacionais Anísio Teixeira (INEP) (coord.), Secretaria de Educação Básica (SEB), Secretaria de Educação a Distância (SEEd), e Fundo Nacional de Desenvolvimento da Educação (FNDE), o que se constata, ao se analisar a sua origem, é que o Programa englobava apenas a oferta de um curso de formação continuada dirigido aos diretores de escolas públicas. Pode-se interpretar que esta ambiguidade em sua formulação é o que levaria à explicitação de "princípios" do curso a ser oferecido, com ampla abrangência, o que parece ser mais adequado a um programa de âmbito federal, conforme segue:

. compromisso com a melhoria da qualidade do ensino público e com a valorização e a capacitação do gestor escolar;

. respeito ao princípio de equidade: um curso com a mesma qualidade, atingindo ao mesmo tempo toda a população-alvo dos Estados brasileiros;

. atendimento ao princípio democrático de integração com a comunidade, descentralização do poder e autonomia da escola;

. formação de rede que possibilite a troca de informações, experiências, vivências e integre os gestores escolares de todo o País.

Este argumento é reforçado quando se observam os objetivos do Projeto Piloto e se constata a redução de amplitude que se efetiva face aos princípios anunciados. Revelam tais objetivos uma perspectiva centrada na visão do diretor de escola como liderança que deve ter uma formação continuada de natureza técnico-instrumental, o que possibilitaria qualificar e otimizar os processos de trabalho no cotidiano escolar. Assim, são objetivos do Projeto:

. garantir formação continuada do gestor escolar para o efetivo exercício da liderança enquanto componente mediador, integrador e catalisador dos esforços da escola para a realização de suas propostas educativas;

. desenvolver instrumentos para apoiar a qualificação dos processos e procedimentos da gestão escolar, tendo em vista a melhoria da qualidade do ensino;

- fomentar o uso da tecnologia como ferramenta gerencial no cotidiano da escola visando ao aperfeiçoamento e otimização dos processos de trabalho.

O curso oferecido abrangia como "público-alvo" gestores, em exercício, de escolas públicas de educação básica, integrantes dos sistemas de ensino estadual e municipal. O Projeto Piloto previa numa primeira etapa envolver quatrocentos gestores, nos seguintes estados e municípios: Ceará, Pernambuco, Bahia, Piauí, Rio Grande do Norte (Região Nordeste); Mato Grosso (Região Centro-Oeste); Espírito Santo (Região Sudeste); Rio Grande do Sul e Santa Catarina (Região Sul); Município de Palmas/TO (Região Norte). 
Tendo a modalidade de educação a distância como carro-chefe da metodologia proposta, o Curso, inserido no ambiente e.Proinfo (SEED/MEC) e estruturado em cinco módulos, previa três encontros presenciais, bem como a utilização de recursos tecnológicos considerados capazes de viabilizar a participação, a integração e a capacitação de diretores das escolas básicas. Tal metodologia permitiria, como afirmado pelos seus formuladores, que os diretores fossem "qualificados no próprio processo de trabalho".

Ao definirem que a participação dos diretores escolares no Curso integra o "próprio processo de trabalho", os formuladores do Programa, mesmo anunciando benefícios aos gestores escolares, afirmam, na proposta metodológica do Curso, contraditoriamente, uma determinada visão de formação continuada de profissionais da educação que atribui a eles a responsabilidade e a gestão do seu aperfeiçoamento e qualificação profissionais. Ao fazê-lo, contribuem para um entendimento limitado da prática pedagógica de formação continuada que certamente resultaria em "mais trabalho" para esses profissionais.

Com a saída do Ministro da Educação Tarso Genro, em julho de 2005, motivada, sobretudo, pelos arranjos do processo eleitoral em curso no país e a assunção do Ministro Fernando Haddad, ocorreram, como é de praxe na dinâmica da política brasileira, re-orientações das políticas e dos procedimentos administrativos internos ministeriais, cuja análise foge ao escopo deste artigo. Interessa, neste texto, destacar a mudança que ocorreu no Programa Escola de Gestores que passou, a partir de janeiro de 2006, para a esfera de coordenação da Secretaria de Educação Básica- SEB deste Ministério, sofrendo várias alterações no tocante aos conteúdos e configuração institucional.

\section{O Programa Nacional Escola de Gestores e a interferência de seto- res organizados dos educadores em sua formulação}

Com a mudança da coordenação do Programa Escola de Gestores para a Secretaria de Educação Básica, ocorreram alterações de rumos quanto à natureza do curso a ser oferecido aos gestores da educação básica, bem como no que concerne ao tipo de instituição responsável pela oferta do mesmo. Os dirigentes da SEB fizeram a opção pela oferta de um curso de pós-graduação lato sensu, especialização em gestão escolar, sob a responsabilidade acadêmica de universidades federais. 
Tomadas essas decisões, a SEB desencadeou o processo de articulação externa ${ }^{4}$ mediante contatos com instituições e órgãos da sociedade civil ANPEd, ANDIFES, CNTE, CONSED, UNDIME, UNICEF -, com o propósito de assegurar sustentação política e acadêmica a esse empreendimento. Com este objetivo, em janeiro de 2006, essas entidades foram convocadas para uma reunião na SEB para apresentação e discussão do Programa de Formação Continuada dos Gestores da Educação Básica.

Nessa reunião, houve empenho da parte dos titulares da ANDIFES $^{5}$ e da $\mathrm{ANPEd}^{6}$ para que a SEB tomasse a decisão de ofertar o curso de especialização de gestão escolar exclusivamente nas universidades federais. A ANPEd propôs que o curso fosse coordenado pelos núcleos de pós-graduação e de pesquisa em educação que desenvolvessem estudos em política e gestão da educação e da escola. Defendeu também a proposta que a formulação do projeto do curso de especialização fosse balizada pelos pesquisadores do Grupo de Trabalho 5 (GT5) - Estado e Política Educacional que congregava a produção na área em que se inseria o curso.

Muito embora estivessem presentes representantes de várias entidades e instituições, com interesses diversificados, prevaleceu esse entendimento, tendo em vista, também, a disposição do Ministério da Educação em estreitar a relação institucional com as IFES.

Em decorrência dessa decisão, a direção da SEB deu início ao processo de formulação do Curso buscando a mediação, sobretudo, da ANDIFES e da ANPEd para a indicação de pesquisadores das IFES que participariam da discussão das diretrizes gerais do curso de especialização em gestão escolar no âmbito do Programa Escola de Gestores. Da reunião realizada com tal objetivo, na SEB, em 7 de março, participaram, dentre outros, os pesquisadores da área indicados pela coordenação do GT5 da ANPEd'.

4 Tal articulação esteve sob a responsabilidade direta do Departamento de Articulação de Sistemas de Ensino e da Coordenação Geral de Articulação e Fortalecimento dos Sistemas de Ensino.

5 O professor Paulo Speller, Presidente da ANDIFES, participou desta reunião da SEB.

6 A professora Márcia Angela Aguiar, Presidente da ANPEd, esteve presente nesta reunião da SEB.

7 Foram indicados e participaram da reunião na SEB, em 7 de março de 2006, os pesquisadores do GT5 da ANPEd: Antonio Cabral Neto (UFRN), Antonio Lisboa (UFRN e vice-coordenador do GT5), Regina Vinhaes Gracindo (UnB e coordenadora do GT5), Márcia Angela Aguiar (UFPE), Luiz de Sousa Júnior (UFPb), Leda Scheibe (UFSC), Vera Perroni (UFRGS), Maria Dilnéia Espíndola (UFMS), João Ferreira (UFG), Marcelo Soares (UFU), Benno Sander (Anpae), Erasto Mendonça (UnB), Nicholas Davies (UFF) e Graça Tavares (UFAL-GT 11 Anped). Vale ressaltar que nessa ocasião a Coordenação do GT5 promoveu uma reunião com os referidos pesquisadores com o objetivo de programar as atividades do GT na reunião anual da Anped que se realizaria em 2006. 
É relevante destacar que essa movimentação motivou o FORUMDIR a iniciar formalmente uma articulação das Faculdades e Centros de Educação das Universidades Públicas para que nas definições internas em cada uma das IFES o curso de especialização em gestão escolar fosse coordenado pelas faculdades e centros de educação, o que não deveria impossibilitar a parceria com outros setores internos, a exemplo dos núcleos de educação a distância.

Em mensagem ${ }^{8}$ enviada às Faculdades e Centros de Educação, o presidente do FORUMDIR chamava a atenção, nessa ocasião, para a disposição evidenciada pela SEB em buscar a colaboração dessas instituições para o desenvolvimento de projetos pedagógicos, bem como alertava os seus dirigentes para a necessidade de ocupar novos espaços no campo da formação dos profissionais da educação, especialmente na formação continuada a distância.

Essa iniciativa do FORUMDIR evidencia, por outro lado, a tensão que se configurava no âmbito do Ministério da Educação com as pressões de alguns setores para que fossem firmados convênios com ONGs ou com instituições do setor privado para a implementação do referido curso.

A movimentação desses setores no espaço de formulação de uma ação governamental que terá repercussão nas universidades federais e nas secretarias estaduais de todos os estados da federação evidenciam os embates que se efetivam no campo da política educacional.

\section{A implementação do curso de especialização em gestão escolar e as implicações no processo de trabalho docente}

O curso de especialização em Gestão Escolar, estruturado na modalidade Educação a Distância, fez parte das ações formativas implementadas pela SEB que visavam ampliar o processo de democratização e de fortalecimento da escola pública. Nesse sentido, pode-se entender o processo participativo de estruturação do curso, a parceria com as IFES e a busca de articulação interinstitucional com as diversas instituições e setores da educação.

Assim, pode ser observada a iniciativa de articulação, em âmbito nacional, do Programa Escola de Gestores da Educação Básica com diferentes instituições e entidades educacionais, em especial a ANPEd, ANDIFES, FORUMDIR,

8 Mensagem enviada pelo titular do FORUMDIR aos diretores das Faculdades e Centros de Educação das Universidades Públicas, em 20 de março de 2006 (Consulta ao Arquivo Profissionais da Educação do Núcleo de Políticas e Gestão da Educação do Programa de Pós-Graduação em Educação da UFPE, em 3/10/09). 
CONSED, UNDIME e IFES, na elaboração e efetivação de suas estratégias de ação. As sucessivas reuniões organizadas pela SEB com estes múltiplos atores do campo educacional revelam a estratégia dos dirigentes deste órgão no sentido de garantir as condições políticas de institucionalização de formação continuada de gestores escolares apoiada pelo Ministério da Educação mediante o estabelecimento dessas parcerias. Desse modo, a SEB buscava operacionalizar um dos compromissos expressos pelo Governo Lula da Silva no sentido de promover a gestão democrática e a efetivação do direito à educação escolar com qualidade social.

Evidentemente, esse processo não é linear. Ao contrário, a gestão da educação constitui um campo eivado de tensões que se expressam também nas lutas internas entre os setores burocráticos do Ministério da Educação e com os parceiros do Programa Escola de Gestores, sobretudo no que concerne aos conteúdos e metodologias de implementação e avaliação do curso de especialização em gestão escolar. Exemplos dessas tensões podem ser visualizados nas mudanças de dirigentes e de equipes técnicas ocorridas na SEB que indiscutivelmente afetaram o desenvolvimento do Programa ${ }^{9}$.

Uma das tensões nesse campo que merece ser aqui examinada diz respeito à participação dos gestores escolares no curso de especialização, nas diversas IFES, e o tempo destinado à realização das atividades previstas. Estruturado na modalidade EAD, o curso tem uma proposta metodológica inovadora no que tange aos tradicionais cursos de especialização ofertados na área, requerendo a participação ativa do cursista em atividades inerentes à gestão do cotidiano escolar.

Reconhecendo que a gestão democrática das unidades escolares constitui uma das dimensões que pode contribuir significativamente para assegurar o direito à educação, o currículo do curso tem como princípio norteador $o$ direito à educação com qualidade social. Este princípio será o horizonte das atividades formativas propostas nas salas-ambientes virtuais ${ }^{10}$ que passaram a integrar o curso na plataforma tecnológica ${ }^{11}$.

9 No período compreendido entre janeiro de 2006 a janeiro de 2009, a SEB teve dois titulares, o Departamento de Articulação e Fortalecimento dos Sistemas de Ensino, com 3 titulares, e a Coordenação Geral de Articulação e fortalecimento dos Sistemas de Ensino do Programa Escola de Gestores, com 4 titulares. Além disso, ocorreram mudanças na estrutura organizacional dessa Secretaria.

10 Nomenclaturas das Salas Ambientes: Introdução ao Ambiente e ao Curso; Projeto Vivencial; Fundamentos do Direito à Educação; Planejamento e Prática da Gestão Escolar; Tópicos Especiais; Oficinas Tecnológicas.

11 Inicialmente o curso de especialização estava hospedado na Plataforma e-Proinfo e, posteriormente, na Plataforma MOODLE. 
No projeto pedagógico original do Curso de Especialização em Gestão Escolar, a sala-ambiente Projeto Vivencial constituiria o núcleo do currículo do curso. Caberia a cada cursista-gestor, sob a orientação do professor responsável, definir e desenvolver, ao longo do curso, um projeto de intervenção vinculado ao Projeto Político-Pedagógico (PPP) da Escola em que exercesse sua atividade profissional como dirigente. Ao mesmo tempo, era previsto o acesso, nas demais salas-ambientes, aos aportes teóricos e metodológicos pertinentes à formulação e desenvolvimento desse projeto no âmbito da escola.

Examinar como se concretiza tal proposta teórico-metodológica possibilita desvelar alguns dos obstáculos que o docente - gestor enfrenta no seu cotidiano de trabalho ao buscar se integrar em programas de formação continuada oferecidos pelo poder público. No projeto original do Curso de Especialização em Gestão Escolar chama a atenção, dentre outros, dois requerimentos necessários ao seu ingresso: o acesso do cursista à Internet; a disponibilidade de, no mínimo, 10 horas semanais, dedicação, ao longo de todo o curso, para o desenvolvimento do projeto pedagógico e demais atividades.

$\mathrm{O}$ atendimento desses requisitos, no entanto, é dificultado por um reconhecido obstáculo: a falta de tempo dos docentes para cumprir as atividades do curso. Essa questão tem se apresentado de forma recorrente nos relatos e avaliações efetivados pelos coordenadores dos cursos de especialização implementados nas IFES. Há uma queixa generalizada da parte dos docentes responsáveis pelas salas-ambientes, como também dos próprios cursistas, nas IFES, sobre os problemas decorrentes do tempo destinado ao cumprimento das tarefas do curso. O que se observa, contudo, é que, apesar de constar como uma exigência a dedicação pelo gestor de 10 horas semanais, ao longo do curso, para o desenvolvimento do projeto e atividades correlatas, não vêm ocorrendo ações das secretarias de educação envolvidas para assegurar essa condição. Para os formuladores da proposta pedagógica do Curso, tal situação, considerada crítica, compromete a operacionalização do currículo do curso, e, logo, a sua filosofia.

Do ponto de vista do trabalho docente, pode-se verificar que, sem a garantia, por parte dos sistemas de ensino, de condições adequadas de tempo, o curso acarretará sobrecarga de trabalho ao docente, que, não dispondo de carga horária de dedicação parcial ou integral ao curso, ver-se-á compelido a sacrificar horas destinadas às suas atividades pessoais para tentar responder às exigências programáticas do curso.

Tal circunstância, provavelmente, contribuirá para elevar o nível de stress a que vem sendo submetido o docente na escola pública ou privada, por excesso de tarefas que lhes são atribuídas, como denunciam recorrentemente a Confederação Nacional dos Trabalhadores em Educação - CNTE e os sindicatos filiados em todos os estados da federação. 
A situação desses docentes-gestores que participam desses cursos parece corroborar a análise feita por Oliveira (2008) quando afirma que:

[...] houve uma dilatação, no plano legal do que seja o pleno exercício das atividades docentes. Agora, o trabalho docente deve contemplar as atividades em sala de aula, as reuniões pedagógicas, a participação na gestão da escola, o planejamento pedagógico, dentre outras atividades. Esse quadro tem resultado em significativa intensificação do trabalho e precarização das relações de emprego, em mudanças que repercutem sobre a identidade e profissão docente (p. 30).

Resolver esse impasse no sentido de, ao mesmo tempo, assegurar o direito à formação continuada dos profissionais da educação e garantir as condições de trabalho que favoreçam esta formação constitui, sem dúvida, um grande desafio que deverá ser enfrentado pelas instâncias e esferas de governo responsáveis pela implementação do Programa Nacional Escola de Gestores.

\section{Considerações finais}

A política nacional de formação continuada de docentes da educação básica envolve vários e importantes aspectos, que vão desde o tipo de colaboração que se estabelece entre os entes federados e as instituições de ensino superior para a oferta de cursos de pós-graduação lato sensu até as questões das condições de trabalho dos docentes.

A proposta de uma política de formação continuada para os docentes tem sido objeto de inúmeros debates que evidenciam aspectos positivos e problemáticos desse processo. De um lado, ao procurar dar concretude ao direito do profissional de educação de aperfeiçoamento permanente, o governo contribui com o estabelecimento de uma política de estado, reivindicada pelos setores organizados dos educadores.

Contudo, de outro lado, tal iniciativa também é visualizada, por alguns setores, como uma ação regulatória do governo federal que interfere na autonomia dos estados e municípios e que irá onerar as demais instâncias governamentais sem que ocorra uma justa retribuição financeira aos esforços despendidos pelos estados e municípios. 
Além disso, é preciso destacar que a própria definição de uma política de formação continuada, como também as suas características, são objetos de disputa entre os vários segmentos a partir de visões diferenciadas com relação ao projeto de Nação, aos projetos educacionais e às práticas pedagógicas. Nesse contexto, o embate mais visível se dá entre uma visão pragmática e instrumental de formação docente mais preocupada em alcançar resultados estatísticos e outra perspectiva de formação docente voltada para a emancipação humana numa sociedade igualitária.

A análise aqui empreendida mostra que o Programa Nacional Escola de Gestores da Educação Básica pode se inserir nesta segunda perspectiva ao priorizar a formação cidadã e a escola pública como espaço privilegiado da formação humana. Ao priorizar a oferta de uma formação pós-graduada aos gestores escolares nessa perspectiva, o governo fez a opção de buscar apoio nas universidades federais, demonstrando reconhecer que tais instituições congregavam a maioria dos pesquisadores com estudos na área em todas as regiões do país, o que facilitaria a oferta dos cursos de especialização em gestão escolar.

Ao assumir esses cursos, as universidades constataram que o sucesso dessa oferta, além da qualidade do projeto pedagógico implementado, dependeria, em grande parte, das condições que as secretarias de educação oferecessem aos gestores no tocante ao tempo dedicado aos estudos. Nos casos em que não são viabilizadas essas condições, os docentes-gestores tendem a arcar individualmente com o ônus da sobrecarga de trabalho, fator inconteste do stress típico da profissão docente, conforme apontam os estudos da área.

Por fim, a experiência do Programa Nacional Escola de Gestores mostra que o êxito de uma política de formação continuada dos docentes está condicionado a vários fatores, sobretudo, aqueles atinentes ao modo como as secretarias de educação tratam essa formação. Ou seja, depende, sobretudo, da prioridade que esta atribui à formação pós-graduada dos docentes ao considerar que o respeito ao direito de aperfeiçoamento permanente do docente e do gestor constitui um requisito fundamental para a construção de uma educação e de uma escola de qualidade capazes de favorecer a formação cidadã. A garantia das condições adequadas que favoreçam a plena inserção desses profissionais nos cursos de pós-graduação constitui um indicador do compromisso institucional das várias instâncias do poder público com a educação brasileira. 


\section{REFERÊNCIAS}

AGUIAR, M. A. S. Política de formação de professores: o que muda nas esferas nacional e local? In: GRACIANO, M. (Org.). O Plano de Desenvolvimento da Educação (PDE). São Paulo: Ação Educativa, 2007, p. 39-42.

AGUIAR, Márcia A. S. A formação do profissional da educação no contexto da reforma educacional brasileira. In: FERREIRA, N. S C. (Org). Supervisão educacional para uma escola de qualidade. São Paulo: Cortez, 1999, p. 183-204.

AGUIAR, Márcia A. S. Gestão da Educação Básica e o fortalecimento dos Conselhos Escolares. Educar em Revista, n. 31, Curitiba: Editora UFPR, 2008, p. 129-144.

AGUIAR. Márcia A.; SILVA, Aida M. M. (Orgs). Retrato da escola no Brasil. Brasília: CNTE, 2004.

BRASIL. Lei $n^{\circ}$ 9.394, de 20 de dezembro de 1996. Estabelece as diretrizes e bases da educação nacional. Disponível em: <http://www.planalto.gob.br/ccivil_03/Leis/ L9394. htm>. Acesso em: out. 2008.

. Lei $n^{\circ} 10.172$, de 9 de janeiro de 2001. Aprova o Plano Nacional de Educação e dá outras providências. Disponível em: < http://www.planalto.gob.br/ccivil_03/leis / leis_2001/101172.htm>. Acesso em: out. 2008.

DOURADO, L. F. Plano Nacional de Educação: avaliações e retomada do protagonismo da sociedade civil organizada na luta pela educação. In: FERREIRA, N. S. C. Políticas públicas e gestão da educação: polêmicas, fundamentos e análises. Brasília: Líber Livros, 2007, p. 21-50.

FREITAS, Helena C. L. A nova política de formação de professores: a prioridade postergada. Educação e Sociedade, Campinas, v. 28, n. 100 - Especial, out. 2007, p. 1203-1230.

OLIVEIRA, Dalila A. O trabalho docente na América latina: Identidade e profissionalização. Revista Retratos da Escola. Brasília, v. 2, n. 2-3, p. 23-39, jan./ dez. 2008.

VEIGA, Ilma P. A; RESENDE, Lúcia M. G. de (Orgs.). Escola: espaço do projeto político-pedagógico. Campinas: Papirus, 1998.

Texto recebido em novembro de 2009.

Texto aprovado em maio de 2010. 